Portland State University

PDXScholar

2018

\title{
United States State-Level Variation in the Use of Neuraxial Analgesia During Labor for Pregnant Women
}

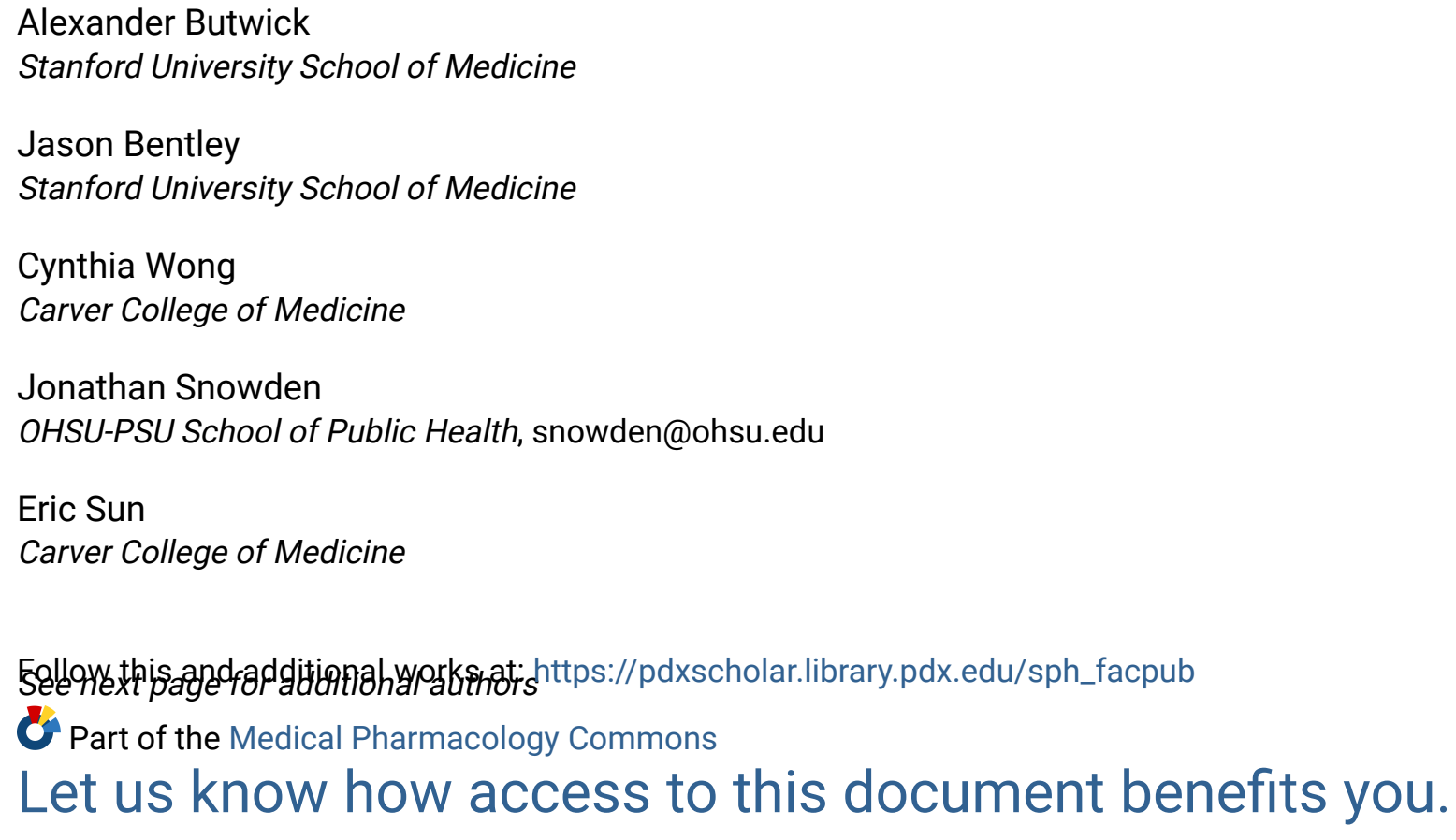

\section{Citation Details}

Butwick, A. J., Bentley, J., Wong, C. A., Snowden, J. M., Sun, E., \& Guo, N. (2018). United States State-Level Variation in the Use of Neuraxial Analgesia During Labor for Pregnant Women. JAMA network open, 1(8), e186567-e186567.

This Article is brought to you for free and open access. It has been accepted for inclusion in OHSU-PSU School of Public Health Faculty Publications and Presentations by an authorized administrator of PDXScholar. Please contact us if we can make this document more accessible: pdxscholar@pdx.edu. 
Authors

Alexander Butwick, Jason Bentley, Cynthia Wong, Jonathan Snowden, Eric Sun, and Nan Guo

This article is available at PDXScholar: https://pdxscholar.library.pdx.edu/sph_facpub/189 


\section{United States State-Level Variation in the Use of Neuraxial Analgesia During Labor for Pregnant Women}

Alexander J. Butwick, MBBS, FRCA, MS; Jason Bentley, PhD; Cynthia A. Wong, MD; Jonathan M. Snowden, PhD; Eric Sun, MD, PhD; Nan Guo, PhD

\begin{abstract}
IMPORTANCE Neuraxial labor analgesia is recognized as the most effective method of providing pain relief during labor. Little is known about variation in the rates of neuraxial analgesia across US states. Identifying the presence and extent of variation may provide insights into practice variation and may indicate where access to neuraxial analgesia is inadequate.
\end{abstract}

OBJECTIVE To test the hypothesis that variation exists in neuraxial labor analgesia use among US states.

DESIGN, SETTING, AND PARTICIPANTS Retrospective, population-based, cross-sectional analysis using US birth certificate data. Participants were 2625950 women who underwent labor in 2015.

MAIN OUTCOMES AND MEASURES State-specific prevalence of neuraxial analgesia per 100 women who underwent labor and variability in neuraxial analgesia use among states, assessed using multilevel multivariable regression modeling with the median odds ratio and the intraclass correlation coefficient to evaluate variation by state.

RESULTS In the study population of 2625950 women, $0.1 \%(n=2010)$ were younger than 15 years, $7.0 \%(n=183546)$ were between the ages of 15 and 19 years, $23.6 \%(n=620118)$ were between the ages of 20 and 24 years, $29.6 \%(n=777957)$ were between the ages of 25 and 29 years, $26.0 \%$ ( $n=683656)$ were between the ages of 30 and 34 years, $11.4 \%(n=298237)$ were between the ages of 35 and 39 years, $2.2 \%(n=57130)$ were between the ages of 40 and 44 years, and $0.1 \%$ ( $n=3296$ ) were between the ages of 45 and 54 years. More than $90 \%$ were privately insured or insured with Medicaid. Neuraxial analgesia was used by $73.1 \%$ ( $n=1920368$ ) of women. After adjustment for antepartum, obstetric, and intrapartum factors, Maine had the lowest neuraxial analgesia prevalence (36.6\%; $95 \% \mathrm{Cl}, 33.2 \%-40.1 \%$ ) and Nevada the highest (80.1\%; $95 \% \mathrm{Cl}, 78.3 \%$ $81.7 \%)$. The adjusted median odds ratio was 1.5 ( $95 \% \mathrm{Cl}, 1.4-1.6)$, and the intraclass correlation coefficient was $5.4 \%(95 \% \mathrm{Cl}, 4.0 \%-7.9 \%)$.

CONCLUSIONS AND RELEVANCE Results of this study suggest that a small portion of the overall variation in neuraxial analgesia use is explained by US states. Unmeasured patient-level and hospitallevel factors likely account for a large portion of the variation between states. Efforts should be made to understand what the main reasons are for this variation and whether the variation influences maternal or perinatal outcomes.

JAMA Network Open. 2018;1(8):e186567.

Corrected on January 18, 2019. doi:10.1001/jamanetworkopen.2018.6567

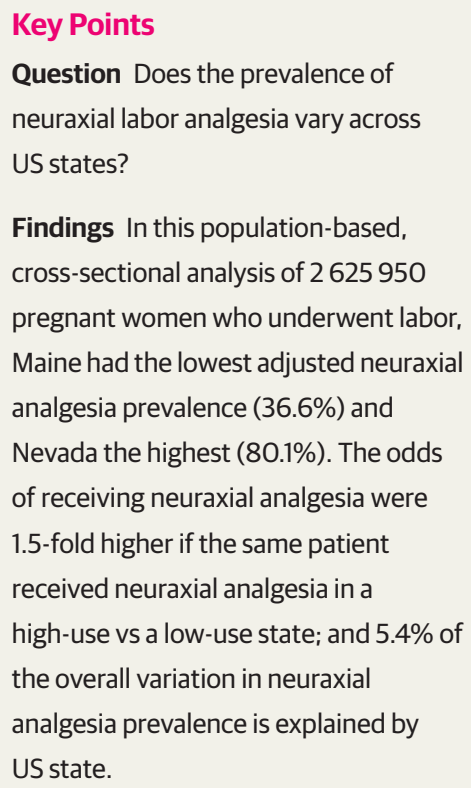

Meaning Results of this study suggest that wide variation exists in neuraxial analgesia use across US states, with a small portion of the overall variation explained by US states.

+ Supplemental content

Author affiliations and article information are listed at the end of this article. 


\section{Introduction}

Pain relief for pregnant women in labor is commonly administered in the form of epidural, spinal, or combined spinal-epidural blockade (collectively referred to as neuraxial analgesia). ${ }^{1}$ Women receiving these techniques have lower pain scores and higher satisfaction scores and are less likely to require additional pain relief compared with women receiving systemic opioid analgesia. ${ }^{2}$ Guidelines for levels of maternal care and for obstetric analgesia and anesthesia published by the American College of Obstetricians and Gynecologists (ACOG) state that anesthesia services should be available to provide labor analgesia in all hospitals that offer maternal care. ${ }^{3,4}$ Although geographical variability has been shown for obstetric procedures, such as abortion availability, ${ }^{5}$ labor induction, ${ }^{6}$ cesarean delivery, ${ }^{7}$ and perinatal outcomes, ${ }^{8,9}$ there is insufficient research to determine whether geographical variation exists across US states in neuraxial analgesia use. Therefore, documenting and understanding geographical variability in the use of neuraxial analgesia are essential undertakings to improve the quality of obstetric anesthesia care.

Multilevel modeling is an approach that is well suited to characterizing the variability in the use of neuraxial analgesia, accounting for both patient-level and state-level factors, and to assessing the contribution of these factors to state-level variability in neuraxial analgesia use. We conducted a population-based analysis of women receiving neuraxial labor analgesia in the United States in 2015. We hypothesized that, after adjustment for patient case mix and state-level measures for the anesthesia workforce, the use of neuraxial analgesia would vary across US states.

\section{Methods}

\section{Study Population and Primary Outcome}

In this retrospective, population-based, cross-sectional analysis, we used US birth certificate data from 2015. These data are publicly available and deidentified; therefore, our analysis was deemed exempt from Stanford University Institutional Review Board approval. This study followed the Strengthening the Reporting of Observational Studies in Epidemiology (STROBE) reporting guideline. We examined data sourced from birth certificates for $100 \%$ of US births from 49 states and the District of Columbia (96.5\% of all births in the United States in 2015). ${ }^{10}$ These states use the 2003 revised US Standard Certificate of Live Birth format. We did not examine 2015 birth data for Connecticut because the state did not use the 2003 revised US Standard Certificate of Live Birth format. The 2003 revised format contains detailed and consistent demographic, medical, and obstetric data, including information on methods of intrapartum analgesia. ${ }^{11}$ Data are entered into the birth certificate by each birth facility according to clinical records and maternal surveys. Details of variables included in the revised birth certificate have been published by the Centers for Disease Control and Prevention. ${ }^{12}$ Each birth certificate contains a check box to indicate whether or not the patient received "epidural or spinal anesthesia during labor." No specific details are included in the birth certificate for the type of neuraxial block (epidural, spinal, or combined spinal-epidural blockade) or other analgesic modalities, such as systemic opioids or inhaled nitrous oxide.

Our study population included women who experienced labor before vaginal delivery or intrapartum cesarean delivery. We excluded women who had a non-US primary residence, an out-ofhospital delivery, multiple pregnancy, cesarean delivery without prior labor, and missing data for mode of delivery or neuraxial labor analgesia use. The final study population comprised 2625950 women (Figure 1). We used a complete case analysis (the highest percentage of missing values among all covariates was $2.5 \%$ for body mass index [BMI]). The frequencies of missingness for each variable by state are listed in the eTable in the Supplement. The primary outcomes were statespecific prevalence of neuraxial analgesia per 100 women who underwent labor and variability in neuraxial analgesia use among states, assessed using multilevel multivariable regression modeling with the median odds ratio (MOR) and the intraclass correlation coefficient (ICC) to evaluate variation by state. 


\section{Patient-Level Factors}

The following patient-level factors were used to build a multivariable model: maternal age, race/ ethnicity, insurance type, highest level of education, marital status, BMI at delivery (classified using the World Health Organization BMI categories ${ }^{13}$ ), prepregnancy diabetes, prepregnancy hypertension, prior live birth, previous cesarean delivery, trimester when prenatal care was initiated, gestational diabetes, gestational hypertension or preeclampsia, eclampsia, gestational age at delivery, labor augmentation, labor induction, birth attendant, and fetal presentation. Details of the patient-level factors are listed in Table 1.

\section{Anesthesia Workforce Measures}

The anesthesia workforce may influence the use of neuraxial labor analgesia; therefore, measures of the anesthesia workforce were incorporated into our model. Based on an approach described by Chang et al, ${ }^{14}$ we quantified the anesthesia workforce as the number of clinicians available for a given population in each state. We developed 2 measures of the anesthesia provider workforce, one for physician anesthesiologists and another for certified registered nurse anesthetists (CRNAs). Data for the total number of clinicians in each state were sourced from the 2015 US Health Resources and Services Administration Area Health Resource File. ${ }^{15}$ Using these data, we calculated ratios of clinicians to births for each state as the number of physician anesthesiologists and CRNAs per 1000 births, respectively.

\section{Statistical Analysis}

Multilevel logistic regression was performed with the GLIMMIX procedure in SAS (version 9.4; SAS Institute Inc) using maximum likelihood estimation based on the Laplace approximation. ${ }^{16}$ Three regression models were fit sequentially. First, we estimated an unconditional or "null" model that included state as a random effect. In the null model (model 1), the random effect may be interpreted as each state's deviation from the mean state-level neuraxial analgesia rate. In model 2, patientlevel factors were added to determine whether the state-level variation remained after accounting

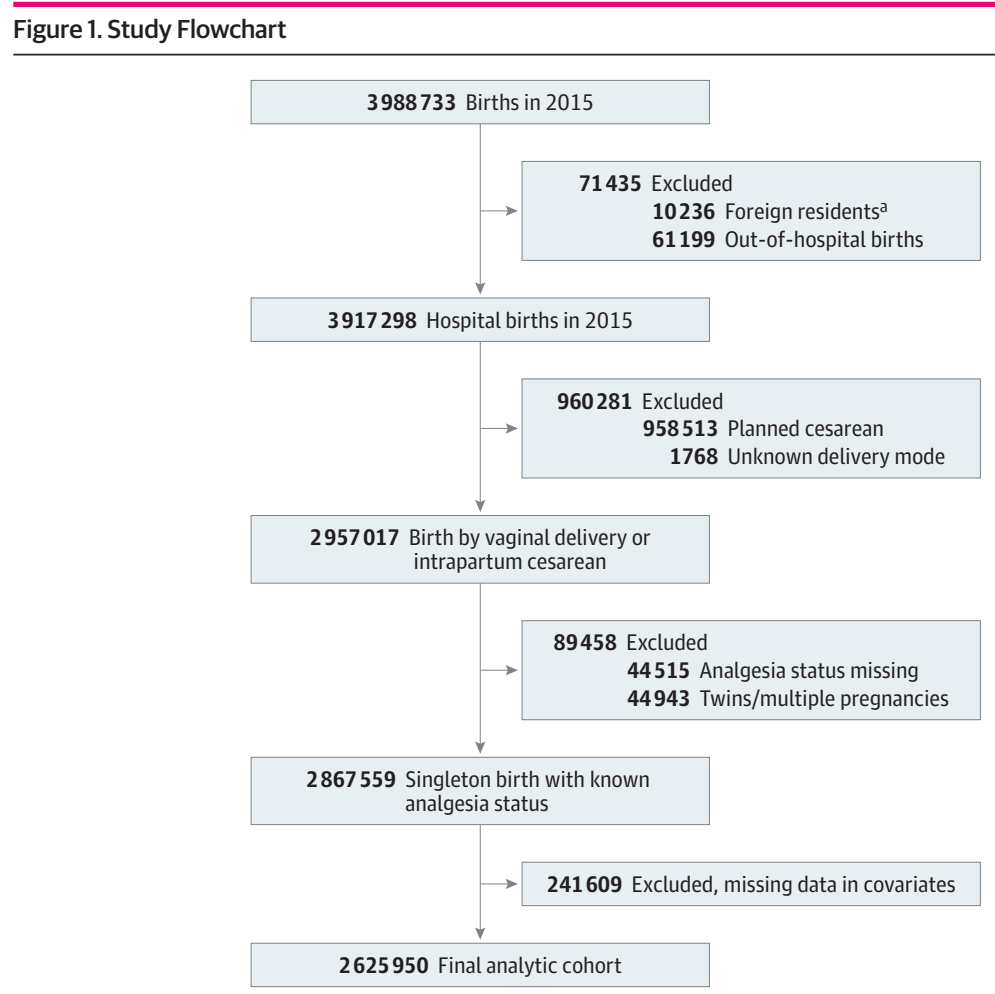

\footnotetext{
a Foreign residents are classified by the Centers for Disease Control and Prevention as women residing in a state that is not 1 of the 50 US states or District of Columbia.
} 


\begin{tabular}{|c|c|c|c|c|}
\hline \multirow[b]{2}{*}{ Variable } & \multicolumn{3}{|l|}{ No. (\%) } & \multirow[b]{2}{*}{$\begin{array}{l}\text { Model } 3 \text { Multilevel } \\
\text { Logistic Regression } \\
\text { Adjusted OR }(95 \% \mathrm{Cl})^{2}\end{array}$} \\
\hline & $\begin{array}{l}\text { Total Study } \\
\text { Population }\end{array}$ & $\begin{array}{l}\text { Women Using } \\
\text { Neuraxial Labor } \\
\text { Analgesia }\end{array}$ & $\begin{array}{l}\text { Women Not Using } \\
\text { Neuraxial Labor } \\
\text { Analgesia }\end{array}$ & \\
\hline \multicolumn{5}{|l|}{ Patient Characteristics } \\
\hline \multicolumn{5}{|l|}{ Maternal age, y } \\
\hline$<15$ & $2010(0.1)$ & $1541(0.1)$ & $469(0.1)$ & $1.71(1.53-1.90)$ \\
\hline $15-19$ & $183546(7.0)$ & $140945(7.3)$ & $42601(6.0)$ & $1.17(1.16-1.19)$ \\
\hline $20-24$ & $620118(23.6)$ & $463646(24.2)$ & $156472(22.2)$ & $1.10(1.09-1.10)$ \\
\hline $25-29$ & 777957 (29.6) & 569055 (29.6) & 208902 (29.6) & 1 [Reference] \\
\hline $30-34$ & $683656(26.0)$ & $493142(25.7)$ & $190514(27.0)$ & $0.96(0.95-0.97)$ \\
\hline $35-39$ & $298237(11.4)$ & 210061 (10.9) & $88176(12.5)$ & $0.93(0.92-0.94)$ \\
\hline $40-44$ & $57130(2.2)$ & $39654(2.1)$ & $17476(2.5)$ & $0.90(0.88-0.92)$ \\
\hline $45-54$ & $3296(0.1)$ & $2324(0.1)$ & $972(0.1)$ & $0.90(0.83-0.97)$ \\
\hline \multicolumn{5}{|l|}{ Race/ethnicity } \\
\hline Non-Hispanic white & $1409509(53.7)$ & $1081556(56.3)$ & $327953(46.5)$ & 1 [Reference] \\
\hline Hispanic & $613435(23.4)$ & 401407 (20.9) & $212028(30.1)$ & $0.75(0.75-0.76)$ \\
\hline Non-Hispanic Asian & $160897(6.1)$ & $117559(6.1)$ & $43338(6.1)$ & $0.99(0.98-1.01)$ \\
\hline Non-Hispanic black & 358007 (13.6) & $261844(13.7)$ & $96163(13.6)$ & $0.86(0.85-0.87)$ \\
\hline Non-Hispanic other & $84102(3.2)$ & $58002(3.0)$ & $26100(3.7)$ & $0.81(0.80-0.83)$ \\
\hline \multicolumn{5}{|l|}{ Insurance type } \\
\hline Private & $1276859(48.6)$ & 980724 (51.1) & $296135(42.0)$ & 1 [Reference] \\
\hline Medicaid & $1150808(43.8)$ & $809383(42.1)$ & 341425 (48.4) & $0.81(0.81-0.82)$ \\
\hline Other & $112405(4.3)$ & $81355(4.2)$ & $31050(4.4)$ & $0.94(0.92-0.95)$ \\
\hline Self-pay & $85878(3.3)$ & $48906(2.6)$ & $36972(5.2)$ & $0.54(0.53-0.55)$ \\
\hline \multicolumn{5}{|l|}{$\begin{array}{l}\text { Highest level of } \\
\text { education }\end{array}$} \\
\hline Grade $\leq 8$ & $87181(3.3)$ & $44232(2.3)$ & $42949(6.1)$ & $0.57(0.56-0.58)$ \\
\hline $\begin{array}{l}\text { Grade 9-12 with no } \\
\text { diploma }\end{array}$ & $298463(11.4)$ & $202227(10.5)$ & $96236(13.6)$ & $0.87(0.87-0.88)$ \\
\hline $\begin{array}{l}\text { High school graduate } \\
\text { or GED completed }\end{array}$ & $668690(25.5)$ & $480676(25.0)$ & $188014(26.6)$ & 1 [Reference] \\
\hline Associate degree & $213058(8.1)$ & $160546(8.4)$ & $52512(7.4)$ & $1.11(1.10-1.13)$ \\
\hline $\begin{array}{l}\text { Some college credit } \\
\text { but not a degree }\end{array}$ & $563712(21.5)$ & $426204(22.2)$ & $137508(19.5)$ & $1.14(1.13-1.15)$ \\
\hline Bachelor's degree & $506740(19.3)$ & $386178(20.1)$ & $120562(17.1)$ & $1.14(1.13-1.15)$ \\
\hline Master's degree & $224024(8.5)$ & $171049(8.9)$ & $52975(7.6)$ & $1.15(1.13-1.16)$ \\
\hline $\begin{array}{l}\text { Doctorate or } \\
\text { professional degree }\end{array}$ & $64082(2.4)$ & $49256(2.6)$ & $14826(2.1)$ & $1.21(1.19-1.24)$ \\
\hline \multicolumn{5}{|l|}{ Marital status } \\
\hline Married & $1532444(58.4)$ & $1123508(58.5)$ & $408936(58.0)$ & 1 [Reference] \\
\hline Unmarried & $1093506(41.6)$ & $796860(41.5)$ & $296646(42.0)$ & $1.12(1.11-1.13)$ \\
\hline \multicolumn{5}{|l|}{$\begin{array}{l}\text { Body mass index at } \\
\text { delivery }^{\mathrm{b}}\end{array}$} \\
\hline $\begin{array}{l}\text { Normal or } \\
\text { underweight }\end{array}$ & $322187(12.3)$ & 223910 (11.6) & $98277(13.9)$ & 1 [Reference] \\
\hline Overweight & 943032 (35.9) & $678751(35.3)$ & $264281(37.5)$ & $1.10(1.09-1.11)$ \\
\hline Obesity class I & 751399 (28.6) & 552265 (28.8) & $199134(28.2)$ & $1.19(1.17-1.20)$ \\
\hline Obesity class II & $370724(14.1)$ & $279889(14.6)$ & $90835(12.9)$ & $1.26(1.25-1.28)$ \\
\hline Obesity class III & $238608(9.1)$ & $185553(9.7)$ & $53055(7.5)$ & $1.33(1.31-1.34)$ \\
\hline Prepregnancy diabetes & $15431(0.6)$ & $12097(0.6)$ & $3334(0.5)$ & $1.13(1.08-1.18)$ \\
\hline $\begin{array}{l}\text { Prepregnancy } \\
\text { hypertension }\end{array}$ & $35540(1.4)$ & $28575(1.5)$ & $6965(1.0)$ & $1.14(1.10-1.17)$ \\
\hline No prior live birth & $1142006(43.5)$ & $920899(48.0)$ & 221107 (31.3) & $1.76(1.75-1.77)$ \\
\hline $\begin{array}{l}\text { Previous cesarean } \\
\text { delivery }\end{array}$ & $86051(3.3)$ & $66047(3.4)$ & $20004(2.8)$ & $1.87(1.84-1.90)$ \\
\hline
\end{tabular}

(continued) 
Table 1. Patient Characteristics and Measures of Association Between Individual and Hospital Characteristics and Neuraxial Labor Analgesia Use (continued)

\begin{tabular}{|c|c|c|c|c|}
\hline \multirow[b]{2}{*}{ Variable } & \multicolumn{3}{|l|}{ No. (\%) } & \multirow[b]{2}{*}{$\begin{array}{l}\text { Model } 3 \text { Multilevel } \\
\text { Logistic Regression } \\
\text { Adjusted OR }(95 \% \mathrm{Cl})\end{array}$} \\
\hline & $\begin{array}{l}\text { Total Study } \\
\text { Population }\end{array}$ & $\begin{array}{l}\text { Women Using } \\
\text { Neuraxial Labor } \\
\text { Analgesia }\end{array}$ & $\begin{array}{l}\text { Women Not Using } \\
\text { Neuraxial Labor } \\
\text { Analgesia }\end{array}$ & \\
\hline \multicolumn{5}{|l|}{$\begin{array}{l}\text { Trimester when } \\
\text { prenatal care } \\
\text { was initiated }\end{array}$} \\
\hline First & $2022474(77.0)$ & $1502462(78.2)$ & $520012(73.7)$ & 1 [Reference] \\
\hline Second & 449955 (17.1) & $315881(16.5)$ & $134074(19.0)$ & $0.87(0.87-0.88)$ \\
\hline Third & $117100(4.5)$ & $81490(4.2)$ & $35610(5.0)$ & $0.87(0.86-0.89)$ \\
\hline No prenatal care & $36421(1.4)$ & $20535(1.1)$ & $15886(2.3)$ & $0.61(0.59-0.62)$ \\
\hline Gestational diabetes & $136329(5.2)$ & $102916(5.4)$ & $33413(4.7)$ & $1.04(1.02-1.05)$ \\
\hline $\begin{array}{l}\text { Gestational } \\
\text { hypertension or } \\
\text { preeclampsia }\end{array}$ & $138358(5.3)$ & $114564(6.0)$ & $23794(3.4)$ & $1.19(1.17-1.20)$ \\
\hline Eclampsia & $4790(0.2)$ & $3941(0.2)$ & $849(0.1)$ & $1.15(1.06-1.24)$ \\
\hline \multicolumn{5}{|l|}{$\begin{array}{l}\text { Gestational age at } \\
\text { delivery, wk }\end{array}$} \\
\hline $37-42$ & 2459720 (93.7) & 1807692 (94.1) & $652028(92.4)$ & 1 [Reference] \\
\hline $24-36$ & $162016(6.1)$ & $111332(5.8)$ & $50684(7.2)$ & $0.82(0.81-0.83)$ \\
\hline$<24$ & $4214(0.2)$ & $1344(0.1)$ & $2870(0.4)$ & $0.17(0.16-0.18)$ \\
\hline Labor augmentation & $710290(27.0)$ & $586970(30.6)$ & $123320(17.5)$ & $2.31(2.30-2.33)$ \\
\hline Labor induction & $819874(31.2)$ & $685271(35.7)$ & $134603(19.1)$ & $2.31(2.29-2.33)$ \\
\hline \multicolumn{5}{|l|}{ Birth attendant } \\
\hline Physician & 2320775 (88.4) & $1739608(90.6)$ & $581167(82.4)$ & 1 [Reference] \\
\hline Midwife & $289862(11.0)$ & $171635(8.9)$ & $118227(16.7)$ & $0.54(0.54-0.55)$ \\
\hline Other & $15313(0.6)$ & $9125(0.5)$ & $6188(0.9)$ & $0.61(0.59-0.63)$ \\
\hline \multicolumn{5}{|l|}{ Fetal presentation } \\
\hline Cephalic & $2581813(98.3)$ & $1887973(98.3)$ & $693840(98.3)$ & 1 [Reference] \\
\hline Breech & $14907(0.6)$ & $10768(0.6)$ & $4139(0.6)$ & $1.19(1.15-1.24)$ \\
\hline Other & $29230(1.1)$ & $21627(1.1)$ & $7603(1.1)$ & $1.07(1.04-1.10)$ \\
\hline \multicolumn{5}{|c|}{ Anesthesia Workforce Measures } \\
\hline \multicolumn{5}{|c|}{$\begin{array}{l}\text { No. of anesthesiologists } \\
\text { per } 1000 \text { births }{ }^{c}\end{array}$} \\
\hline $6.12-12.02$ & $250948(9.6)$ & $173428(9.0)$ & $77520(11.0)$ & 1 [Reference] \\
\hline $12.09-13.91$ & $640216(24.4)$ & $482377(25.1)$ & $157839(22.4)$ & $1.50(1.06-2.14)$ \\
\hline $14.14-15.85$ & $300363(11.4)$ & $239475(12.5)$ & $60888(8.6)$ & $1.59(1.12-2.25)$ \\
\hline $15.87-18.62$ & $847667(32.3)$ & $585548(30.5)$ & $262119(37.1)$ & $1.20(0.83-1.73)$ \\
\hline $19.64-35.23$ & $586756(22.3)$ & 439540 (22.9) & $147216(20.9)$ & $1.05(0.74-1.48)$ \\
\hline \multicolumn{5}{|l|}{$\begin{array}{l}\text { No. of CRNAs } \\
\text { per } 1000 \text { births }\end{array}$} \\
\hline $4.58-8.49$ & $727396(27.7)$ & $513135(26.7)$ & $214261(30.4)$ & 1 [Reference] \\
\hline $8.53-12.41$ & $371557(14.1)$ & $263353(13.7)$ & $108204(15.3)$ & $0.80(0.56-1.14)$ \\
\hline $12.62-21.19$ & $684418(26.1)$ & $519062(27.0)$ & $165356(23.4)$ & $1.06(0.74-1.51)$ \\
\hline $23.32-29.87$ & $488127(18.6)$ & $354759(18.5)$ & 133368 (18.9) & $0.87(0.61-1.25)$ \\
\hline $30.19-38.31$ & $354452(13.5)$ & 270059 (14.1) & $84393(12.0)$ & $0.96(0.66-1.36)$ \\
\hline
\end{tabular}

Abbreviations: CRNAs, certified registered nurse anesthetists; GED, general equivalency diploma; OR, odds ratio.

a Adjusted for maternal age, race/ethnicity, insurance type, highest level of education, marital status, body mass index at delivery, prepregnancy diabetes, prepregnancy hypertension, prior live birth, previous cesarean delivery, trimester when prenatal care was initiated, gestational diabetes, gestational hypertension or preeclampsia, eclampsia, gestational age at delivery, labor augmentation, labor induction, birth attendant, number of anesthesiologists per 1000 births, and number of CRNAs per 1000 births.

${ }^{b}$ Body mass index (calculated as weight in kilograms divided by height in meters squared) categories are as follows: normal or underweight (<24.9), overweight (25-29.9), obesity class I (30-34.9), obesity class II (35-39.9), and obesity class III ( $\geq 40$ ). c Ranges are quintiles.

for patient-level factors. In model 3, state-level anesthesiologists and CRNAs workforce measures were added to model 2 to determine how much of the state-level variation can be explained by anesthesia workforce measures. Because of a nonlinear association between each state-level workforce measure and our outcome, and for greater ease in interpretation, we categorized each workforce measure using quintiles.

For each model, we summarized the between-state variation using the random-effects variance, the ICC, and the MOR. ${ }^{17-20}$ The ICC represents the proportion of the total variance in neuraxial analgesia use attributable to US states after accounting for differences in patients (case mix). The MOR is interpreted as the median value of the odds ratio between a state with a higher 
likelihood of neuraxial analgesia use and the state with the lower likelihood when randomly picking 2 states from the sample. In our study, the MOR indicates the extent to which the individual probability of neuraxial analgesia is determined by state and is directly comparable to the odds ratios for patient-level factors. Details of the calculations of state-level adjusted prevalence, the ICC, and the MOR are presented as eMethods in the Supplement. We calculated 95\% Cls for the MOR and the ICC. We used the estimated random effects from model 1 and model 2 (before and after adjustment for patient-level factors) to describe the variation in neuraxial analgesia prevalence across states. These data are presented as heat maps and caterpillar plots.

Indications for neuraxial analgesia are not available in the birth certificate, and some patients who underwent intrapartum cesarean delivery may have received de novo neuraxial blockade for surgical anesthesia. Therefore, to assess the robustness of our findings, we repeated our primary analysis among women who underwent vaginal delivery and women who underwent intrapartum cesarean delivery separately. Statistical analysis was performed with SAS (version 9.4; SAS Institute Inc), and figures were generated in R (version 3.3; R Foundation for Statistical Computing).

\section{Results}

We identified 3988733 births in 2015. We excluded 1031716 deliveries because of residency outside of the United States, out-of-hospital births, cesarean deliveries without labor, and unknown delivery modes. We also excluded 44515 deliveries with missing data for neuraxial use and 44943 twins or higher multiple pregnancies. Finally, we excluded 241609 women who had missing data in any covariates. A flow diagram of women who met our exclusion criteria and our final analytic sample is shown in Figure 1. Our final analytic sample comprised 2625950 deliveries. In the study population of 2625950 women, $0.1 \%(n=2010)$ were younger than 15 years, $7.0 \%(n=183546)$ were between the ages of 15 and 19 years, $23.6 \%(n=620118)$ were between the ages of 20 and 24 years, $29.6 \%$ ( $n=777957)$ were between the ages of 25 and 29 years, $26.0 \%(n=683656)$ were between the ages of 30 and 34 years, $11.4 \%(n=298237)$ were between the ages of 35 and 39 years, $2.2 \%$ ( $n=57130$ ) were between the ages of 40 and 44 years, and $0.1 \%(n=3296)$ were between the ages of 45 and 54 years. More than $90 \%$ were privately insured or insured with Medicaid. Among our final analytic sample, 1920368 (73.1\%) received neuraxial labor analgesia. Table 1 lists descriptive characteristics of the final analytic sample.

Table 1 lists the characteristics of women who did and did not receive neuraxial analgesia, with the adjusted odds ratios from the multilevel model that included patient-level factors and anesthesia workforce measures (model 3). Intrapartum factors most strongly associated with neuraxial analgesia were labor augmentation and labor induction. Women with a previous cesarean delivery were more likely to receive neuraxial analgesia compared with women with no history of cesarean delivery. Compared with women with prior live births, women with no prior live birth were more likely to receive neuraxial analgesia. Sociodemographic factors inversely associated with neuraxial analgesia were older maternal age, nonwhite race and Hispanic ethnicity, no private insurance or no insurance, twelfth grade or less as the highest level of education, and late or no prenatal care. Compared with physician birth attendants, the odds of receiving neuraxial analgesia were reduced for midwives and other birth attendants. We observed no clear "dose-response" association between the number of anesthesiologists per 1000 births or the number of CRNAs per 1000 births with neuraxial analgesia.

\section{Variation in Statewide Prevalence of Neuraxial Analgesia Use}

Figure 2 shows heat maps for the prevalence of neuraxial analgesia by state before and after adjustment for patient-level factors, respectively. Caterpillar plots are shown in eFigure 1 and eFigure 2 in the Supplement. After adjustment for antepartum, obstetric, and intrapartum factors, Maine had the lowest adjusted neuraxial analgesia prevalence (36.6\%; 95\% Cl, 33.2\%-40.1\%) and

(1. JAMA Network Open. 2018;1(8):e186567. doi:10.1001/jamanetworkopen.2018.6567 
Nevada the highest (80.1\%; $95 \% \mathrm{Cl}, 78.3 \%-81.7 \%$ ). The adjusted MOR was 1.5 (95\% Cl, 1.4-1.6), and the ICC was $5.4 \%$ (95\% Cl, 4.0\%-7.9\%).

Table 2 lists the MORs and ICCs of the 3 models. The MOR in model 1 was 1.5 ( $95 \% \mathrm{Cl}, 1.4-1.6)$, indicating that women's odds of receiving neuraxial labor analgesia varied by state. Therefore, if a women moved to a state with a high probability of neuraxial labor analgesia, the odds of receiving neuraxial labor analgesia would increase by $50 \%$. However, only a small percentage (ICC, 5.4\%) of the total variance was explained by state. The MOR and ICC did not decrease after adjustment for patient-level factors (model 2). In model 3, the MOR was $1.4(95 \% \mathrm{Cl}, 1.3-1.6)$, indicating that, after controlling for patient-level factors, anesthesia workforce measures explained only a small amount of state-level variation.

Figure 2. State-Specific and Adjusted State-Specific Prevalence of Neuraxial Analgesia Use in 2015

A Crude prevalence of neuraxial analgesia use

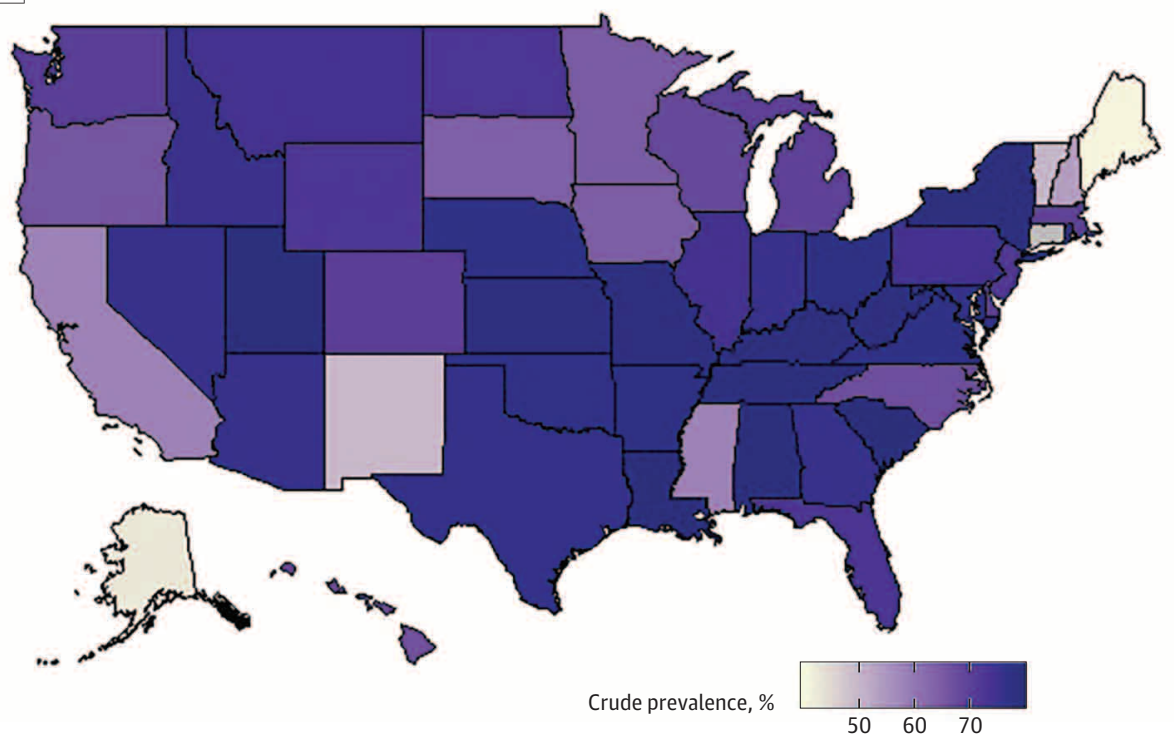

B Adjusted prevalence of neuraxial analgesia use

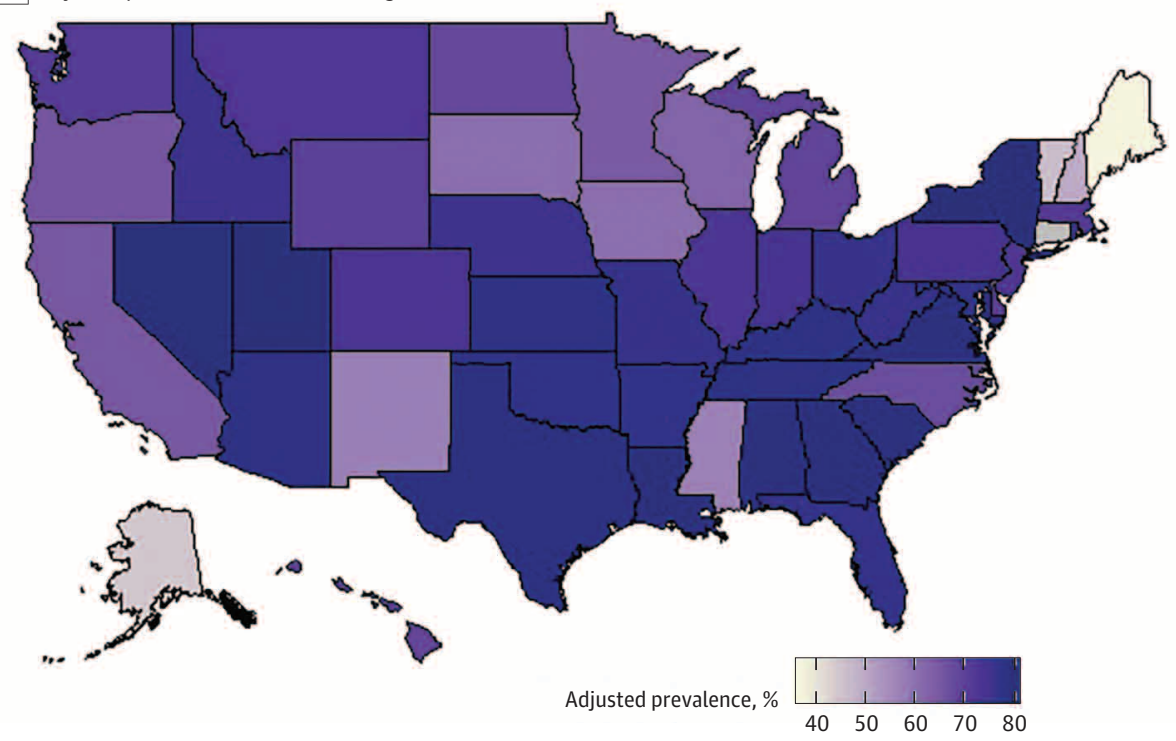

A, Heat map of crude state-specific prevalence of neuraxial analgesia use across US states in 2015. B, Heat map of adjusted state-specific prevalence of neuraxial analgesia use across US states in 2015. Connecticut did not provide data. 


\section{Subgroup Analysis}

We performed subgroup analysis to examine the prevalence of neuraxial analgesia use according to mode of delivery. The unadjusted prevalences of neuraxial analgesia use among women who underwent vaginal delivery and intrapartum cesarean delivery were $71.1 \%$ and $89.7 \%$, respectively. Heat maps and caterpillar plots of the prevalence of neuraxial analgesia use after adjusting for patient-level factors across US states among women who underwent vaginal delivery and intrapartum cesarean delivery are shown in eFigure 3 and eFigure 4 in the Supplement. Among the vaginal deliveries, the adjusted state-level prevalence ranged from $34.7 \%(95 \% \mathrm{Cl}, 31.4 \%-38.2 \%)$ in Maine to $78.6 \%$ (95\% Cl, 76.7\%-80.3\%) in Nevada. Among cesarean births, the adjusted statelevel prevalence ranged from $26.9 \%(95 \% \mathrm{Cl}, 21.9 \%-32.9 \%)$ in South Dakota to $92.6 \%(95 \% \mathrm{Cl}$, 91.5\%-93.4\%) in Idaho. The adjusted odds ratios derived from model 3 stratified according to delivery mode are listed in Table 3. In model 2 for vaginal delivery, we observed a MOR similar to that in our primary model (MOR, 1.5; 95\% Cl, 1.4-1.6). In model 2 for intrapartum cesarean delivery, we observed a greater degree of residual variation that was not explained by patient-level factors (MOR, 2.1; $95 \% \mathrm{Cl}, 1.8-2.4)$.

\section{Discussion}

In this study that included 2625950 women who underwent labor before giving birth, we identified substantial variation in the prevalence of neuraxial analgesia use, with a 2-fold difference in the highest prevalence state vs the lowest prevalence state. After adjusting for patient-level factors, only $5.4 \%$ of the statewide variation was attributable to the state. The MOR was greater than 1 in all models, suggesting that other unmeasured patient-level and hospital-level factors likely explain a large portion of the variance in neuraxial labor analgesia use across US states.

Our study could not determine why variation in neuraxial analgesia rates exists across states. One possible explanation for the residual variation is that the availability, type, and quality of obstetric anesthesia care in hospitals may vary among states. In states with a low prevalence of neuraxial analgesia use, such as Maine, Vermont, and Mississippi, a high proportion of the population lives in rural communities $\left(61 \%, 61 \%\right.$, and $51 \%$, respectively $\left.{ }^{21}\right)$. Research indicates that disparities exist in local access to obstetric services in vulnerable local communities ${ }^{22}$ and that rural hospitals increasingly face obstetric workforce challenges. ${ }^{23}$ Women who deliver in rural hospitals, which typically have low obstetric volumes, ${ }^{24}$ may face challenges in gaining access to obstetric anesthesia care. Based on data from the 2011 Obstetric Anesthesia Workforce Survey, ${ }^{25}$ hospitals with fewer than 500 annual births have lower rates of neuraxial analgesia compared with hospitals with 1500 or more annual births (66\% vs $82 \%$, respectively). In addition, only $15 \%$ of hospitals with fewer than

\begin{tabular}{llll}
\hline \multicolumn{4}{l}{ Table 2. Measures of Variation and Clustering in Neuraxial Labor Analgesia Use in the United States in 2015} \\
\hline Variable & ${\text { Model } 1^{\mathrm{a}}}^{\mathrm{a}}$ & ${\text { Model } 2^{\mathrm{b}}}^{\mathrm{b}}$ & Model 3 $^{\mathrm{c}}$ \\
\hline State-level variance (SE) & $0.173(0.035)$ & $0.186(0.037)$ & $0.147(0.030)$ \\
\hline MOR $(95 \% \mathrm{Cl})$ & $1.5(1.4-1.6)$ & $1.5(1.4-1.7)$ & $1.4(1.3-1.6)$ \\
\hline ICC $(95 \% \mathrm{Cl}), \%$ & $5.0(3.5-7.4)$ & $5.4(4.0-7.9)$ & $4.3(2.8-6.4)$ \\
\hline
\end{tabular}

Abbreviations: ICC, intraclass correlation coefficient; MOR, median odds ratio.

a Null model.

${ }^{\mathrm{b}}$ Adjusted for maternal age, race/ethnicity, insurance type, highest level of education, marital status, body mass index at delivery, prepregnancy diabetes, prepregnancy hypertension, prior live birth, previous cesarean delivery, trimester when prenatal care was initiated, gestational diabetes, gestational hypertension or preeclampsia, eclampsia, gestational age at delivery, labor augmentation, labor induction, birth attendant, and fetal presentation.

c Adjusted for maternal age, race/ethnicity, insurance type, highest level of education, marital status, body mass index at delivery, prepregnancy diabetes, prepregnancy hypertension, prior live birth, previous cesarean delivery, trimester when prenatal care was initiated, gestational diabetes, gestational hypertension or preeclampsia, eclampsia, gestational age at delivery, labor augmentation, labor induction, birth attendant, number of anesthesiologists per 1000 births, and number of CRNAs per 1000 births. 

Table 3. Measures of Association Between Patient Characteristics, Anesthesia Workforce Measures,
and Neuraxial Labor Analgesia Use Stratified by Delivery Mode in the United States in 2015

\begin{tabular}{|c|c|c|}
\hline \multirow[b]{2}{*}{ Variable } & \multicolumn{2}{|l|}{ Adjusted OR $(95 \% \mathrm{Cl})$} \\
\hline & Vaginal Delivery $(n=2344368)^{a}$ & Cesarean Delivery $(n=281582)^{a}$ \\
\hline \multicolumn{3}{|l|}{ Patient Characteristics } \\
\hline \multicolumn{3}{|l|}{ Maternal age, $y$} \\
\hline$<15$ & $1.86(1.66-2.08)$ & $1.13(0.73-1.75)$ \\
\hline $15-19$ & $1.23(1.22-1.25)$ & $0.98(0.92-1.03)$ \\
\hline $20-24$ & $1.12(1.11-1.13)$ & $1.01(0.97-1.05)$ \\
\hline $25-29$ & 1 [Reference] & 1 [Reference] \\
\hline $30-34$ & $0.95(0.94-0.95)$ & $1.05(1.02-1.09)$ \\
\hline $35-39$ & $0.90(0.89-0.91)$ & $1.08(1.03-1.13)$ \\
\hline $40-44$ & $0.85(0.83-0.86)$ & $1.05(0.97-1.14)$ \\
\hline $45-54$ & $0.82(0.75-0.90)$ & $0.98(0.76-1.25)$ \\
\hline \multicolumn{3}{|l|}{ Race/ethnicity } \\
\hline Non-Hispanic white & 1 [Reference] & 1 [Reference] \\
\hline Hispanic & $0.73(0.73-0.74)$ & $1.11(1.06-1.15)$ \\
\hline Non-Hispanic Asian & $0.97(0.96-0.99)$ & $1.18(1.11-1.25)$ \\
\hline Non-Hispanic black & $0.83(0.82-0.84)$ & $1.17(1.12-1.21)$ \\
\hline Non-Hispanic other & $0.81(0.79-0.82)$ & $0.82(0.77-0.88)$ \\
\hline \multicolumn{3}{|l|}{ Insurance type } \\
\hline Private & 1 [Reference] & 1 [Reference] \\
\hline Medicaid & $0.81(0.80-0.81)$ & $0.87(0.84-0.90)$ \\
\hline Other & $0.94(0.92-0.95)$ & $0.95(0.89-1.02)$ \\
\hline Self-pay & $0.54(0.53-0.55)$ & $0.72(0.67-0.78)$ \\
\hline \multicolumn{3}{|l|}{ Highest level of education } \\
\hline Grade $\leq 8$ & $0.56(0.55-0.57)$ & $0.69(0.64-0.75)$ \\
\hline Grade 9-12 with no diploma & $0.87(0.86-0.88)$ & $0.95(0.90-0.99)$ \\
\hline High school graduate or GED completed & 1 [Reference] & 1 [Reference] \\
\hline Associate degree & $1.12(1.10-1.13)$ & $1.09(1.03-1.14)$ \\
\hline Some college credit but not a degree & $1.14(1.13-1.15)$ & $1.07(1.03-1.11)$ \\
\hline Bachelor's degree & $1.14(1.13-1.16)$ & $1.20(1.14-1.25)$ \\
\hline Master's degree & $1.15(1.13-1.16)$ & $1.27(1.20-1.35)$ \\
\hline Doctorate or professional degree & $1.23(1.20-1.25)$ & $1.27(1.16-1.40)$ \\
\hline \multicolumn{3}{|l|}{ Marital status } \\
\hline Married & 1 [Reference] & 1 [Reference] \\
\hline Unmarried & $1.12(1.11-1.13)$ & $1.02(0.99-1.05)$ \\
\hline \multicolumn{3}{|l|}{ Body mass index at delivery ${ }^{b}$} \\
\hline Normal or underweight & 1 [Reference] & 1 [Reference] \\
\hline Overweight & $1.09(1.08-1.10)$ & $1.08(1.03-1.14)$ \\
\hline Obesity class I & $1.16(1.14-1.17)$ & $1.09(1.03-1.15)$ \\
\hline Obesity class II & $1.22(1.21-1.23)$ & $1.06(1.01-1.13)$ \\
\hline Obesity class III & $1.26(1.25-1.28)$ & $1.02(0.96-1.08)$ \\
\hline Prepregnancy diabetes & $1.08(1.03-1.13)$ & $1.05(0.94-1.16)$ \\
\hline Prepregnancy hypertension & $1.14(1.10-1.17)$ & $0.94(0.87-1.02)$ \\
\hline No prior live birth & $1.62(1.61-1.64)$ & $1.42(1.38-1.47)$ \\
\hline Previous cesarean delivery & $1.55(1.52-1.58)$ & $1.18(1.12-1.23)$ \\
\hline \multicolumn{3}{|l|}{ Trimester when prenatal care was initiated } \\
\hline First & 1 [Reference] & 1 [Reference] \\
\hline Second & $0.87(0.86-0.88)$ & $0.90(0.87-0.93)$ \\
\hline Third & $0.87(0.86-0.88)$ & $0.91(0.85-0.96)$ \\
\hline No prenatal care & $0.60(0.58-0.61)$ & $0.90(0.80-1.01)$ \\
\hline Gestational diabetes & $1.03(1.01-1.04)$ & $0.97(0.92-1.01)$ \\
\hline Gestational hypertension or preeclampsia & $1.20(1.18-1.22)$ & $0.91(0.88-0.95)$ \\
\hline
\end{tabular}

(continued) 


\begin{tabular}{|c|c|c|}
\hline \multirow[b]{2}{*}{ Variable } & \multicolumn{2}{|l|}{ Adjusted OR $(95 \% \mathrm{Cl})$} \\
\hline & Vaginal Delivery $(n=2344368)^{a}$ & Cesarean Delivery $(n=281582)^{a}$ \\
\hline Eclampsia & $1.15(1.05-1.26)$ & $0.89(0.74-1.07)$ \\
\hline \multicolumn{3}{|c|}{ Gestational age at delivery, wk } \\
\hline $37-42$ & 1 [Reference] & 1 [Reference] \\
\hline $24-36$ & $0.82(0.81-0.83)$ & $0.74(0.71-0.78)$ \\
\hline$<24$ & $0.21(0.20-0.23)$ & $0.27(0.17-0.41)$ \\
\hline Labor augmentation & $2.34(2.32-2.35)$ & $1.93(1.87-2.00)$ \\
\hline Labor induction & $2.35(2.33-2.37)$ & $1.31(1.27-1.35)$ \\
\hline \multicolumn{3}{|l|}{ Birth attendant } \\
\hline Physician & 1 [Reference] & 1 [Reference] \\
\hline Midwife & $0.58(0.57-0.58)$ & $0.74(0.63-0.87)$ \\
\hline Other & $0.63(0.61-0.65)$ & $1.14(0.80-1.64)$ \\
\hline \multicolumn{3}{|l|}{ Fetal presentation } \\
\hline Cephalic & 1 [Reference] & 1 [Reference] \\
\hline Breech & $0.69(0.65-0.73)$ & $0.77(0.73-0.82)$ \\
\hline Other & $0.95(0.92-0.97)$ & $0.97(0.90-1.04)$ \\
\hline \multicolumn{3}{|c|}{ Anesthesia Workforce Measures } \\
\hline \multicolumn{3}{|c|}{ No. of anesthesiologists per 1000 births $^{c}$} \\
\hline $6.12-12.02$ & 1 [Reference] & 1 [Reference] \\
\hline $12.09-13.91$ & $1.02(0.71-1.46)$ & $1.12(0.55-2.32)$ \\
\hline $14.14-15.85$ & $1.40(0.98-1.99)$ & $1.49(0.77-2.88)$ \\
\hline $15.87-18.62$ & $1.08(0.75-1.56)$ & $1.00(0.52-1.92)$ \\
\hline $19.64-35.23$ & $0.90(0.63-1.28)$ & $1.53(0.79-2.98)$ \\
\hline \multicolumn{3}{|c|}{ No. of CRNAs per 1000 births $^{c}$} \\
\hline $4.58-8.49$ & 1 [Reference] & 1 [Reference] \\
\hline $8.53-12.41$ & $0.89(0.62-1.28)$ & $0.70(0.37-1.34)$ \\
\hline $12.62-21.19$ & $1.10(0.77-1.56)$ & $0.99(0.51-1.89)$ \\
\hline $23.32-29.87$ & $0.93(0.66-1.33)$ & $0.88(0.43-1.77)$ \\
\hline $30.19-38.31$ & $1.02(0.71-1.46)$ & $0.64(0.33-1.25)$ \\
\hline
\end{tabular}

Abbreviations: CRNAs, certified registered nurse anesthetists; GED, general equivalency diploma; OR, odds ratio.

a Adjusted for maternal age, race/ethnicity, insurance type, highest level of education, marital status, body mass index at delivery, prepregnancy diabetes, prepregnancy hypertension, prior live birth, previous cesarean delivery, trimester when prenatal care was initiated, gestational diabetes, gestational hypertension or preeclampsia, eclampsia, gestational age at delivery, labor augmentation, labor induction, birth attendant, number of anesthesiologists per 1000 births, and number of CRNAs per 1000 births.

${ }^{\mathrm{b}}$ Body mass index (calculated as weight in kilograms divided by height in meters squared) categories are as follows: normal or underweight (<24.9), overweight (25-29.9), obesity class I (30-34.9), obesity class II (35-39.9), and obesity class III ( $\geq 40)$.

c Ranges are quintiles.

500 annual births have in-house obstetric anesthesia staff. ${ }^{25}$ In low-volume hospitals, especially those located in states with large rural populations, CRNAs more commonly deliver obstetric anesthesia care than physician anesthesiologists. ${ }^{23,25}$ There is a need for further research to determine whether limited access to obstetric anesthesia care, particularly in low-volume hospitals, explains the low prevalence of neuraxial analgesia use in rural US states.

Although we accounted for a number of patient-level factors previously shown to be associated with neuraxial analgesia use, such as race/ethnicity, insurance type, and highest level of education, ${ }^{26-31}$ other patient-level factors may account for some of the variation among states. For example, lower health literacy, cultural and religious beliefs, antenatal participation in childbirth education classes, and patient preferences may influence a patient's decision to use neuraxial analgesia. ${ }^{31,32}$ Patients and obstetric care providers may not be aware of recent advances in neuraxial 
analgesia and the potential benefits of these advances on maternal outcomes. ${ }^{33}$ For example, neuraxial analgesia regimens using low concentrations of local anesthetic are associated with a lower risk of instrumental vaginal delivery compared with older regimens using higher-concentration solutions. ${ }^{34,35}$ Therefore, knowledge and biases about the effects of neuraxial analgesia among patients and health care professionals may vary by state. In addition, we could not assess whether states with high use rates of non-neuraxial analgesia techniques (eg, nitrous oxide) have low rates of neuraxial analgesia.

Findings from our secondary analysis of women who underwent vaginal delivery were consistent with our primary findings. However, we observed that women who underwent cesarean delivery had a high overall adjusted prevalence of neuraxial analgesia use (89.7\%). Several reasons may explain this finding. Some women who received de novo neuraxial blockade for surgical anesthesia may have been misclassified as receiving neuraxial labor analgesia. Pregnant women in labor at risk of intrapartum cesarean delivery may have been advised to receive neuraxial analgesia to allow for later surgical anesthesia with an epidural top-up dose. ${ }^{36}$ Neuraxial labor analgesia is associated with cesarean delivery in observational studies but not in randomized clinical trials. ${ }^{37} \mathrm{~A}$ likely explanation is that the request for neuraxial analgesia is a marker for increased risk for cesarean delivery. Dysfunctional labor and a large and malpositioned fetus likely increase labor pain and the request for labor analgesia and are also associated with risk for cesarean delivery. ${ }^{37}$ For the subset of women herein with cesarean delivery, the range in the prevalence of neuraxial analgesia across states was wide (26.9\%-92.6\%), with a moderately high MOR of 2.1. The reason for these findings is uncertain; further work is needed to examine whether obstetric anesthetic practices differ across states for pregnant women in labor who are "at risk" for intrapartum cesarean delivery.

\section{Strengths and Limitations}

The main strengths of our study are the large size of the data set comprising recent data on neuraxial analgesia. Evidence from the national data set also allowed us to account for a large number of patient-level factors in our multilevel model.

Nonetheless, the study has several limitations. First, despite concerns about the accuracy of diagnoses in birth certificates, ${ }^{38-40}$ prior evidence demonstrates high sensitivity (85\%-96\%) and a low false discovery rate (14\%-20\%) of neuraxial analgesia documentation in birth certificates. ${ }^{38}$ To our knowledge, specificity of neuraxial analgesia documentation has not been previously reported. However, we presume that the specificity is high because it is unlikely that neuraxial labor analgesia would be reported on a birth certificate for a patient who did not receive neuraxial labor analgesia. Second, despite the superior analgesia provided by neuraxial techniques, other potential direct and indirect effects of neuraxial analgesia on mother-centric outcomes (eg, satisfaction, postpartum recovery, and breastfeeding) have not been well studied. These outcomes are not captured in birth certificate data and thus could not be examined in our analysis. To model these outcomes, valid clinical data are required, as are other data for appropriate risk adjustment. Third, no studies to date have validated our statewide anesthesia workforce measures. These measures assume that all clinicians practice to a similar degree, despite differences in key attributes, such as level of training and years of experience. Another complicating factor is that CRNAs can practice independently in some states, but in other states physicians must supervise or direct CRNAs' practice. Fourth, the study did not include hospital-level data; therefore, we could not determine the hospital type (teaching or community), frequency of neuraxial analgesia use at each hospital, or the number of anesthesia providers at the hospital level. Given that ACOG's 2015 guidelines ${ }^{3}$ for the regionalization of maternal care state that anesthesia services should be available in all facilities, including those providing basic maternal care, further research is necessary to determine whether the prevalence of neuraxial analgesia use is a proxy for the availability of high-quality consultative obstetric anesthesia care. ${ }^{41}$ Fifth, we did not assess neuraxial labor analgesia use across US counties. An examination of county-level variation would provide finer resolution of the geographical variation of neuraxial labor 
analgesia use. Similarly, we did not have geographical data to determine the density of anesthesia providers across counties or other designated geographical zones.

\section{Conclusions}

We examined national birth certificate data and found wide variation in the prevalence of neuraxial analgesia use across US states. Only a small portion of the overall variation was explained by statelevel factors. Unmeasured patient-level and hospital-level factors likely account for a large portion of variance between states. With ACOG guidelines stating that anesthesia services should be available to provide labor analgesia in all hospitals that provide maternal care, ${ }^{3,4}$ efforts should be made to better understand the main reasons for the variation and whether this variation influences maternal or perinatal outcomes.

\section{ARTICLE INFORMATION}

Accepted for Publication: November 12, 2018.

Open Access: This is an open access article distributed under the terms of the CC-BY License. (C) 2018 Butwick AJ et al. JAMA Network Open.

Published: December 28, 2018. doi:10.1001/jamanetworkopen.2018.6567

Correction: This article was corrected on January 18, 2019, to delete extraneous data regarding Arkansas in the Discussion.

Corresponding Author: Alexander J. Butwick, MBBS, FRCA, MS, Department of Anesthesiology, Perioperative and Pain Medicine, Stanford University School of Medicine, Mail Code 5640, 300 Pasteur Dr, Stanford, CA 94305 (ajbut@stanford.edu).

Author Affiliations: Department of Anesthesiology, Perioperative and Pain Medicine, Stanford University School of Medicine, Stanford, California (Butwick, Sun, Guo); Quantitative Sciences Unit, Stanford University School of Medicine, Stanford, California (Bentley); Department of Anesthesia, Roy J. and Lucille A. Carver College of Medicine, University of lowa, lowa City (Wong); School of Public Health, Oregon Health \& Science UniversityPortland State University, Portland (Snowden).

Author Contributions: Dr Butwick had full access to all of the data in the study and takes responsibility for the integrity of the data and the accuracy of the data analysis.

Concept and design: All authors.

Acquisition, analysis, or interpretation of data: Butwick, Bentley, Snowden, Guo.

Drafting of the manuscript: Butwick, Wong, Snowden, Guo.

Critical revision of the manuscript for important intellectual content: All authors.

Statistical analysis: Butwick, Bentley, Snowden, Sun, Guo.

Administrative, technical, or material support: Butwick, Snowden.

Supervision: Butwick, Bentley.

Conflict of Interest Disclosures: Dr Butwick reported receiving funds for consultation from Instrumentation Laboratory. Dr Sun reported receiving grants from the National Institute on Drug Abuse. No other disclosures were reported.

Funding/Support: This study was supported and funded internally by the Department of Anesthesia and the Department of Obstetrics and Gynecology at Stanford University School of Medicine. Dr Butwick is supported by award 1K23HD070972 from the Eunice Kennedy Shriver National Institute of Child Health and Human Development.

Role of the Funder/Sponsor: The funding sources had no role in the design and conduct of the study; collection, management, analysis, and interpretation of the data; preparation, review, or approval of the manuscript; and decision to submit the manuscript for publication.

Meeting Presentation: This work was presented in part as an oral presentation at the 50th Annual Meeting of the Society for Obstetric Anesthesia and Perinatology; May 12, 2018; Miami, Florida. 


\section{REFERENCES}

1. Hawkins JL. Epidural analgesia for labor and delivery. N Eng/ J Med. 2010;362(16):1503-1510. doi:10.1056/ NEJMct0909254

2. Anim-Somuah M, Smyth RM, Cyna AM, Cuthbert A. Epidural versus non-epidural or no analgesia for pain management in labour. Cochrane Database Syst Rev. 2018;5:CD000331.

3. American College of Obstetricians and Gynecologists. Obstetric Care Consensus No. 2: levels of maternal care. Obstet Gynecol. 2015;125(2):502-515. doi:10.1097/01.AOG.0000460770.99574.9f

4. American College of Obstetricians and Gynecologists. Practice Bulletin No. 177: obstetric analgesia and anesthesia. Obstet Gynecol. 2017;129(4):e73-e89. doi:10.1097/AOG.0000000000002018

5. Bearak JM, Burke KL, Jones RK. Disparities and change over time in distance women would need to travel to have an abortion in the USA: a spatial analysis. Lancet Public Health. 2017;2(11):e493-e500. doi:10.1016/S24682667(17)30158-5

6. Nippita TA, Trevena JA, Patterson JA, Ford JB, Morris JM, Roberts CL. Variation in hospital rates of induction of labour: a population-based record linkage study. BMJ Open. 2015;5(9):e008755. doi:10.1136/bmjopen-2015008755

7. Kozhimannil KB, Law MR, Virnig BA. Cesarean delivery rates vary tenfold among US hospitals; reducing variation may address quality and cost issues. Health Aff (Millwood). 2013;32(3):527-535. doi:10.1377/hlthaff. 2012.1030

8. Glance LG, Dick AW, Glantz JC, et al. Rates of major obstetrical complications vary almost fivefold among US hospitals. Health Aff (Millwood). 2014;33(8):1330-1336. doi:10.1377/hlthaff.2013.1359

9. Sebastião YV, Womack LS, López Castillo H, et al. Hospital variations in unexpected complications among term newborns. Pediatrics. 2017;139(3):e20162364. doi:10.1542/peds.2016-2364

10. Martin JA, Hamilton BE, Osterman MJ, Driscoll AK, Mathews TJ. Births: final data for 2015. Natl Vital Stat Rep. 2017;66(1):1-70.

11. Osterman MJ, Martin JA, Mathews TJ, Hamilton BE. Expanded data from the new birth certificate, 2008. Natl Vital Stat Rep. 2011;59(7):1-28.

12. Centers for Disease Control and Prevention. Revisions of the U.S. standard certificates and reports. https://www. cdc.gov/nchs/nvss/revisions-of-the-us-standard-certificates-and-reports.htm. Published 2017. Accessed January 31, 2018.

13. World Health Organization. Obesity: Preventing and Managing the Global Epidemic: Report of a WHO Consultation. Geneva, Switzerland: World Health Organization; 2000.

14. Chang $\mathrm{CH}$, Stukel TA, Flood AB, Goodman DC. Primary care physician workforce and Medicare beneficiaries' health outcomes. JAMA. 2011;305(20):2096-2104. doi:10.1001/jama.2011.665

15. National Center for Health Workforce Analysis. Area Health Resource File (AHRF). https://bhw.hrsa.gov/healthworkforce-analysis/data\#analytics. Published 2017. Accessed August 21, 2018.

16. Tierney L, Kadane JB. Accurate approximations for posterior moments and marginal densities. J Am Stat Assoc. 1986;81(393):82-86. doi:10.1080/01621459.1986.10478240

17. Larsen K, Merlo J. Appropriate assessment of neighborhood effects on individual health: integrating random and fixed effects in multilevel logistic regression. Am J Epidemiol. 2005;161(1):81-88. doi:10.1093/aje/kwi017

18. Larsen K, Petersen JH, Budtz-Jørgensen E, Endahl L. Interpreting parameters in the logistic regression model with random effects. Biometrics. 2000;56(3):909-914. doi:10.1111/j.0006-341X.2000.00909.x

19. Merlo J, Chaix B, Yang M, Lynch J, Råstam L. A brief conceptual tutorial on multilevel analysis in social epidemiology: interpreting neighbourhood differences and the effect of neighbourhood characteristics on individual health. J Epidemiol Community Health. 2005;59(12):1022-1028. doi:10.1136/jech.2004.028035

20. Merlo J, Chaix B, Ohlsson $\mathrm{H}$, et al. A brief conceptual tutorial of multilevel analysis in social epidemiology: using measures of clustering in multilevel logistic regression to investigate contextual phenomena. J Epidemiol Community Health. 2006;60(4):290-297. doi:10.1136/jech.2004.029454

21. US Census Bureau, US Department of Commerce. 2010 Census. https://www.census.gov/programs-surveys/ decennial-census/decade.2010.html. Published 2010. Accessed July 5, 2018.

22. Hung $P$, Henning-Smith CE, Casey MM, Kozhimannil KB. Access to obstetric services in rural counties still declining, with 9 percent losing services, 2004-14. Health Aff (Millwood). 2017;36(9):1663-1671. doi:10.1377/ hlthaff.2017.0338

23. Kozhimannil KB, Casey MM, Hung P, Han X, Prasad S, Moscovice IS. The rural obstetric workforce in US hospitals: challenges and opportunities. J Rural Health. 2015;31(4):365-372. doi:10.1111/jrh.12112 
24. Kozhimannil KB, Hung P, Prasad S, Casey M, McClellan M, Moscovice IS. Birth volume and the quality of obstetric care in rural hospitals. J Rural Health. 2014;30(4):335-343. doi:10.1111/jrh.12061

25. Traynor AJ, Aragon M, Ghosh D, et al. Obstetric Anesthesia Workforce Survey: a 30-year update. Anesth Analg. 2016;122(6):1939-1946. doi:10.1213/ANE.0000000000001204

26. Glance LG, Wissler R, Glantz C, Osler TM, Mukamel DB, Dick AW. Racial differences in the use of epidural analgesia for labor. Anesthesiology. 2007;106(1):19-25. doi:10.1097/00000542-200701000-00008

27. Hueston WJ, McClaflin RR, Mansfield CJ, Rudy M. Factors associated with the use of intrapartum epidural analgesia. Obstet Gynecol. 1994;84(4):579-582.

28. Obst TE, Nauenberg E, Buck GM. Maternal health insurance coverage as a determinant of obstetrical anesthesia care. J Health Care Poor Underserved. 2001;12(2):177-191. doi:10.1353/hpu.2010.0780

29. Liu N, Wen SW, Manual DG, Katherine W, Bottomley J, Walker MC. Social disparity and the use of intrapartum epidural analgesia in a publicly funded health care system. Am J Obstet Gynecol. 2010;202(3):273.e1-273.e8. doi: 10.1016/j.ajog.2009.10.871

30. Rust G, Nembhard WN, Nichols $M$, et al. Racial and ethnic disparities in the provision of epidural analgesia to Georgia Medicaid beneficiaries during labor and delivery. Am J Obstet Gynecol. 2004;191(2):456-462. doi:10.1016/ j.ajog.2004.03.005

31. Toledo P, Caballero JA. Racial and ethnic disparities in obstetrics and obstetric anesthesia in the United States. Curr Anesthesiol Rep. 2013;3(4):292-299. doi:10.1007/s40140-013-0035-4

32. Echevarria GC, Grant GJ, Chung Y, Lax J. Survey of nulliparous parturients' attitudes regarding timing of epidural analgesia initiation. J Clin Anesth. 2017;41:106-111. doi:10.1016/j.jclinane.2017.06.008

33. Ituk U, Wong CA. Epidural labor analgesia: whence come our patients' misconceptions? J Clin Anesth. 2017; 42:84-85. doi:10.1016/j.jclinane.2017.07.012

34. Wang TT, Sun S, Huang SQ. Effects of epidural labor analgesia with low concentrations of local anesthetics on obstetric outcomes: a systematic review and meta-analysis of randomized controlled trials. Anesth Analg. 2017; 124(5):1571-1580. doi:10.1213/ANE.0000000000001709

35. Sultan P, Murphy C, Halpern S, Carvalho B. The effect of low concentrations versus high concentrations of local anesthetics for labour analgesia on obstetric and anesthetic outcomes: a meta-analysis. Can J Anaesth. 2013;60 (9):840-854. doi:10.1007/s12630-013-9981-z

36. Depuydt $E$, Van de Velde M. Unplanned cesarean section in parturients with an epidural catheter in-situ: how to obtain surgical anesthesia? Acta Anaesthesiol Belg. 2013;64(2):61-74.

37. Wong CA. Neuraxial labor analgesia: does it influence the outcomes of labor? Anesth Analg. 2017;124(5): 1389-1391. doi:10.1213/ANE.0000000000001867

38. Martin JA, Wilson EC, Osterman MJ, Saadi EW, Sutton SR, Hamilton BE. Assessing the quality of medical and health data from the 2003 birth certificate revision: results from two states. Nat/ Vital Stat Rep. 2013;62(2):1-19.

39. Reichman NE, Schwartz-Soicher O. Accuracy of birth certificate data by risk factors and outcomes: analysis of data from New Jersey. Am J Obstet Gynecol. 2007;197(1):32.e1-32.e8. doi:10.1016/j.ajog.2007.02.026

40. Roohan PJ, Josberger RE, Acar J, Dabir P, Feder HM, Gagliano PJ. Validation of birth certificate data in New York State. J Community Health. 2003;28(5):335-346. doi:10.1023/A:1025492512915

41. Mhyre JM, Bateman BT. Stemming the tide of obstetric morbidity: an opportunity for the anesthesiologist to embrace the role of peridelivery physician. Anesthesiology. 2015;123(5):986-989. doi:10.1097/ALN.

0000000000000847

SUPPLEMENT.

eTable. Frequencies of Missingness for Each Variable by State

eMethods. Statistical Approach Used in the Random-Effects Models

eFigure 1. Caterpillar Plot of Crude Prevalence of Neuraxial Analgesia by State

eFigure 2. Caterpillar Plot of Adjusted Prevalence of Neuraxial Analgesia by State

eFigure 3. Caterpillar Plots of Adjusted Prevalence of Neuraxial Analgesia by State for Vaginal Delivery and Cesarean Delivery Cohorts

eFigure 4. Heat Maps of Adjusted Prevalence of Neuraxial Analgesia by State for Vaginal Delivery and Cesarean Delivery Cohorts 